\title{
Land-sea surface air temperature contrast on the western coast of Sumatra Island during an active phase of the Madden- Julian Oscillation
}

\author{
Peiming $\mathrm{Wu}^{1^{*}} \mathrm{D}$, Shuichi Mori ${ }^{1}$ and Fadli Syamsudin ${ }^{2}$
}

\begin{abstract}
The land-sea surface temperature contrast on the western coast of Sumatra Island was examined using observation data obtained from the pre-Years of the Maritime Continent (YMC) field campaign from November to December 2015. Surface observations showed that, on most days, strong daytime solar radiation caused a pronounced diurnal cycle in surface air temperatures on the island, even during the local active phase of the Madden-Julian Oscillation (MJO). Sudden drops in surface air temperature occurred frequently on the island in the late afternoon and over the sea at nighttime, accompanied by precipitation. Temperatures on the island were higher than those over the sea during the daytime and lower in the night and early morning. Prior to the local active phase of the MJO, dual maxima in the land-sea surface air temperature contrast occurred in the evening and early morning. During the local active phase of the $\mathrm{MJO}$, in spite of cloudy conditions, there were still large land-sea temperature contrasts during the daytime and in the early morning. In addition to the nighttime radiative cooling of the land surface, decreases in air temperature over the land due to precipitation cooling and the lower solar insolation in the MJO active phase caused the larger temperature differences in the morning. These results suggest that the decrease in air temperature caused by precipitation cooling had a substantial effect on the land-sea surface air temperature contrast on the western coast of Sumatra Island, particularly during an active phase of the MJO.
\end{abstract}

Keywords: Air temperature, Land-sea temperature contrast, Precipitation, Land and sea breeze, Sumatra Island, Diurnal cycle, Madden-Julian Oscillation (MJO)

\section{Introduction}

The Maritime Continent consists of many large and small islands with a complex topography, surrounded by warm and shallow oceans. The difference in the heat capacity between the sea and land can have a great impact on the weather due to the formation of sea and land breezes. The most fundamental mode of atmospheric variability over the Maritime Continent is the diurnal cycle, which is generated by the land-sea temperature contrast (Hara et al. 2009; Yamanaka 2016). The Madden-Julian Oscillation (MJO) is the largest modulator of atmospheric intraseasonal variability in the

\footnotetext{
* Correspondence: pmwu@jamstec.go.jp

${ }^{1} J a p a n$ Agency for Marine-Earth Science and Technology, 2-15

Natsushima-cho, Yokosuka-City, Kanagawa 237-0061, Japan

Full list of author information is available at the end of the article
}

tropics. The MJO has been demonstrated to influence weather over the Maritime Continent at various spatial and temporal scales.

The MJO influences tropical convection by providing an envelope of enhanced or suppressed convection. When an active phase of the MJO propagates eastwards from the Indian Ocean to the Maritime Continent, the MJO's influence on the diurnal cycle of convection causes considerable variations in precipitation over the islands and their surroundings (e.g., Peatman et al. 2014; Birch et al. 2016, Wu et al. 2017). Both the amplitude and phase of the diurnal cycle of rainfall on the island are modulated by the category of the MJO (Rauniyar and Walsh 2011). Using satellite-derived brightness, temperature, and rainfall, Peatman et al. (2014) showed that MJO propagation throughout the Maritime 
Continent is not smooth, with gaps in the MJO envelopes aligned with the islands. Based on numerical simulations, Birch et al. (2016) explained the reasons for the differences in the mean rainfall anomaly over the land and sea by scale interactions between the MJO-related large-scale environment and mesoscale circulation.

The mesoscale circulation, that is, land-sea breezes, is a result of the differences in air temperature between the land and the adjacent sea that are driven by the unequal heating and cooling of land and sea surfaces. To study the scale interaction between the large-scale circulation and the thermally induced local circulations, observation data over both the islands and the seas are necessary. However, most of the previous observations of the diurnal cycles of wind and cloud activity in the Maritime Continent region have been conducted only on the islands (e.g., Wu et al. 2003; Araki et al. 2006; Wu et al. 2008). There are insufficient observation data over the sea to verify the results of numerical simulations reported in previous studies. Exactly how the MJO interacts with local processes, such as sea and land breeze circulations, to influence precipitation over the region is not well understood.

To improve our understanding of convection over the Maritime Continent and its relation to the MJO and local atmospheric circulations, we performed intensive observations as part of the pre-Years of the Maritime Continent (YMC) field campaign on the western coast of Sumatra Island from November to December 2015. Land-based observations at Bengkulu on the western coast and ship-based observations over the sea off the western coast of the island were conducted simultaneously. A surface meteorological dataset with high temporal resolution was constructed for both the land and sea from these observations. The aims of the present study were therefore to examine the variations of air temperature over the western coast of Sumatra Island and to clarify the land-sea surface temperature contrast in an active phase of the MJO, using the observation data obtained from the field campaign.

\section{Methods/Experimental}

Land-based observations were conducted at Bengkulu on the western coast of Sumatra Island, and ship-based observations were conducted over the sea $50 \mathrm{~km}$ off the western coast (Fig. 1). Surface meteorological observations, radar observations, and balloon soundings at intervals of $3 \mathrm{~h}$ were performed at Bengkulu Meteorological Observatory for 47 successive days from 9 November to 25 December 2015. The observation site is located on the coastal plain about $4 \mathrm{~km}$ from the shore, at an elevation of $16 \mathrm{~m}$ above sea level. Surface meteorological variables, including atmospheric pressure, temperature, relative humidity, wind direction and speed, rainfall, and global

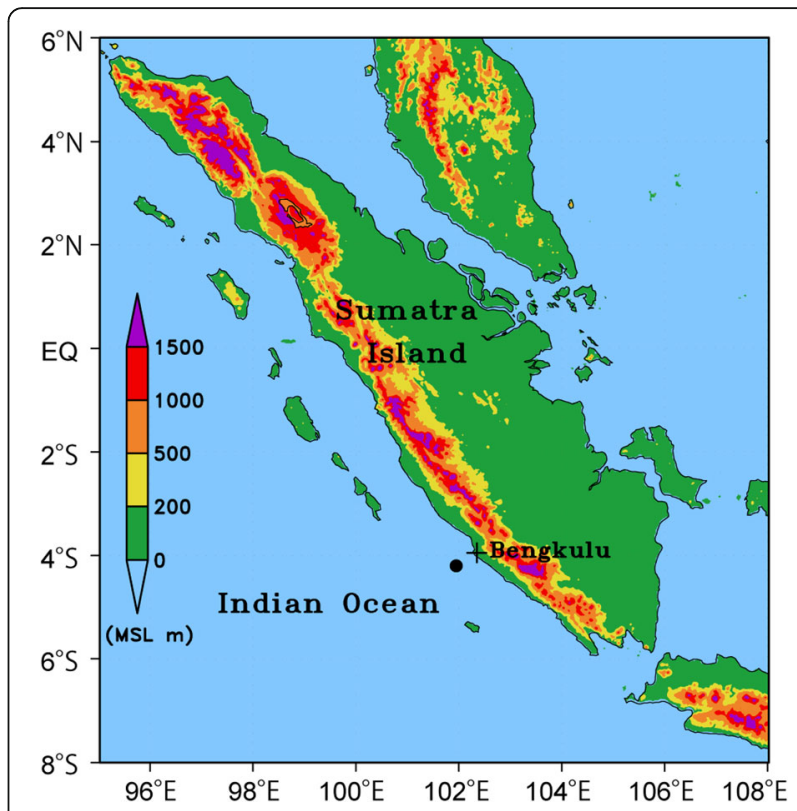

Fig. 1 Topography of Sumatra Island and its surroundings and the locations of Bengkulu Meteorological Observatory (cross) and the research vessel Mirai (closed circle). Shading denotes terrain elevation. MSL is meters above sea level

solar radiation, were measured at intervals of 1 min using an automatic weather station (MAWS 201, Vaisala, Finland). Rainfall was measured by a tipping bucket rain gauge, with a sensitivity of 1 tip per $0.2 \mathrm{~mm}$.

Stationary ship observations were made by the research vessel Mira at a fixed point $4^{\circ} 04^{\prime} 00^{\prime \prime} \mathrm{S}, 101^{\circ} 54^{\prime}$ 00" E from 23 November to 17 December 2015. A Cband meteorological radar was used, and 3-hourly radiosonde observations were conducted. Surface meteorological parameters were measured by the Mirai Surface Meteorological observation (SMet) system and the Shipboard Oceanographic and Atmospheric Radiation (SOAR) measurement system. Air temperature and relative humidity were measured by thermometer sensors (HMP155, Vaisala, Finland) installed in the compass deck at $21 \mathrm{~m}$ altitude from the sea surface. Rainfall rate was measured by a capacitive rain gauge (Model-50202, R. M. Young, USA) and an optical rain gauge (ORG-815DS, Osi, USA) on the compass deck at $19 \mathrm{~m}$ altitude from the sea surface. Short- and long-wave downward radiations were measured by a radiometer (MS-802, Eko Seiki, Japan) on the radar mast. Sea surface temperature was measured by a thermometer (RFN2-0, Koshin Denki, Japan) at an inlet of $5 \mathrm{~m}$ depth from the sea surface. Data were collected and processed by a KOAC-7800 weather data processor made by Koshin-Denki, Japan. Details of the ship-based observations can be found in the MIRAI MR15-04 Cruise report (JAMSTEC 2016). The present study used data for the 
sea surface and sea air temperatures, rainfall, and global solar radiation obtained from the observations.

\section{Results and discussion}

Diurnal variations of surface air temperature, rainfall, and solar radiation on the western coast of Sumatra Island

The oceanic and atmospheric features in December 2015 indicated strong and mature El Niño conditions (e.g., Deser and Wallace 1990). Sea surface temperatures were well above average across the central and eastern equatorial Pacific. Widespread enhanced convection developed across the central Pacific and suppressed convection over the Maritime Continent. Meanwhile, a positive Indian Ocean Dipole (IOD) event (Saji et al. 1999) occurred during the boreal summer and autumn in 2015 and then weakened rapidly. The Dipole Mode Index indicated a transition from the positive to negative IOD phase in December 2015. Sea surface temperatures were close to normal across the tropical Indian Ocean; seas to the west of Sumatra Island were warm, as usual.

During early December 2015, enhanced convection developed over the central Indian Ocean, while suppressed convection persisted over the Maritime Continent. Then, in mid-December, the MJO signal overcame the El NiñoSouthern Oscillation background state over the Maritime Continent region. Enhanced convection developed and shifted east across the Maritime Continent and the westcentral Pacific, indicating a steady eastward propagation of the robust MJO signal. The MJO index (Wheeler and Hendon 2004) showed that the enhanced convective phase was centered on the western Maritime Continent from 13 to 22 December 2015 (Wu et al. 2017).

The time series of hourly total rainfall, hourly averaged surface air temperature, and global solar radiation during the period from 23 November to 17 December 2015 are shown in Fig. 2. Rainfall occurred at Bengkulu on 17 days during the 25-day observation period, i.e., on roughly 2 out of every 3 days. Prior to the local active phase of the MJO until 12 December, most of the rainfall occurred over a short time period of 1 to $2 \mathrm{~h}$ during the late afternoon and evening. Meanwhile, a daily maximum hourly mean global solar radiation greater than $800 \mathrm{~W} \mathrm{~m}^{-2}$ was observed on most days, although on 8 December, daily maximum values of less than $400 \mathrm{~W} \mathrm{~m}^{-2}$ were recorded. On days with rain, strong solar radiation was still observed because rainfall occurred mostly during the late afternoon and evening.

The typical diurnal cycle of surface air temperature and precipitation at Bengkulu on the western coast of Sumatra Island is shown for 25 November and 1, 3, and 15 December 2015 at time intervals of $1 \mathrm{~min}$ in Fig. 3. The daily minimum air temperature was observed at about $0600 \mathrm{LT}$ on these days, and the temperatures increased rapidly from about 0700 LT, i.e., soon after sunrise. The daily maximum air temperature occurred during the several hours before and after noon. The air temperature remained high during the daytime, with short time fluctuations. Then, a sudden drop in the air temperature occurred in the late afternoon, starting about 10 min before precipitation was observed at the observation site. The air temperature decreased rapidly from about 29 to $24{ }^{\circ} \mathrm{C}$ in under $30 \mathrm{~min}$, and thereafter, the air temperature remained at around $24{ }^{\circ} \mathrm{C}$ during and after the precipitation. Daily maximum air temperatures above $30{ }^{\circ} \mathrm{C}$ and daily minimum air temperatures below $24{ }^{\circ} \mathrm{C}$ were observed during the observation period.

November and December are in the annual rainy season of the region (Hamada et al. 2002). In the mid-latitudes, diurnal variations in surface air temperature are usually weak during the rainy season because cloud cover prevents the land from heating rapidly in the daytime and cooling rapidly at night. However, the situation in the near-equatorial area of western Sumatra Island is unique. As described previously, before the active phase of the $\mathrm{MJO}$, rainfall on the western coast of the island occurs mostly over a short time in the late afternoon and evening. The sky is almost cloudless over most areas of the island in the morning and early afternoon, even on days with heavy rain. Strong solar radiation was observed on most days, with the result that surface air temperature increased greatly during the morning hours. During the local active phase of the MJO, i.e., 13 to 17 December 2015 (except for 16 December), surface air temperatures at Bengkulu still displayed a clear diurnal cycle, with a maximum occurring during the several hours before and after noon.

Previous studies have shown that when the MJO main convective envelope is over the Indian Ocean, rainfall and its diurnal cycle over the land in the Maritime Continent reach their maxima due to an increase in the atmospheric instability caused by strong solar insolation in the clearer skies and moistening environment (e.g., Fujita et al. 2011; Peatman et al. 2014; Birch et al. 2016). During the daytime, the upslope winds driven by diurnal heating at the slope surface of the mountains on Sumatra Island reinforce the sea breeze, with the result that a notable thermally induced local circulation develops on the western coast on a daily basis, frequently resulting in convection over the island at similar times in the afternoon (Wu et al. 2003; Wu et al. 2009). Wu et al. (2017) examined the occurrence and movement of convection over the island prior to and during an active phase of the MJO in December 2015, using radar observation data obtained from the pre-YMC field campaign. Their results showed that prior to the active phase of the $\mathrm{MJO}$ in early December, convection with heavy rain occurred regularly over Sumatra Island in the afternoon and migrated westward to the sea west of the island in the evening. Results from surface meteorological observations 

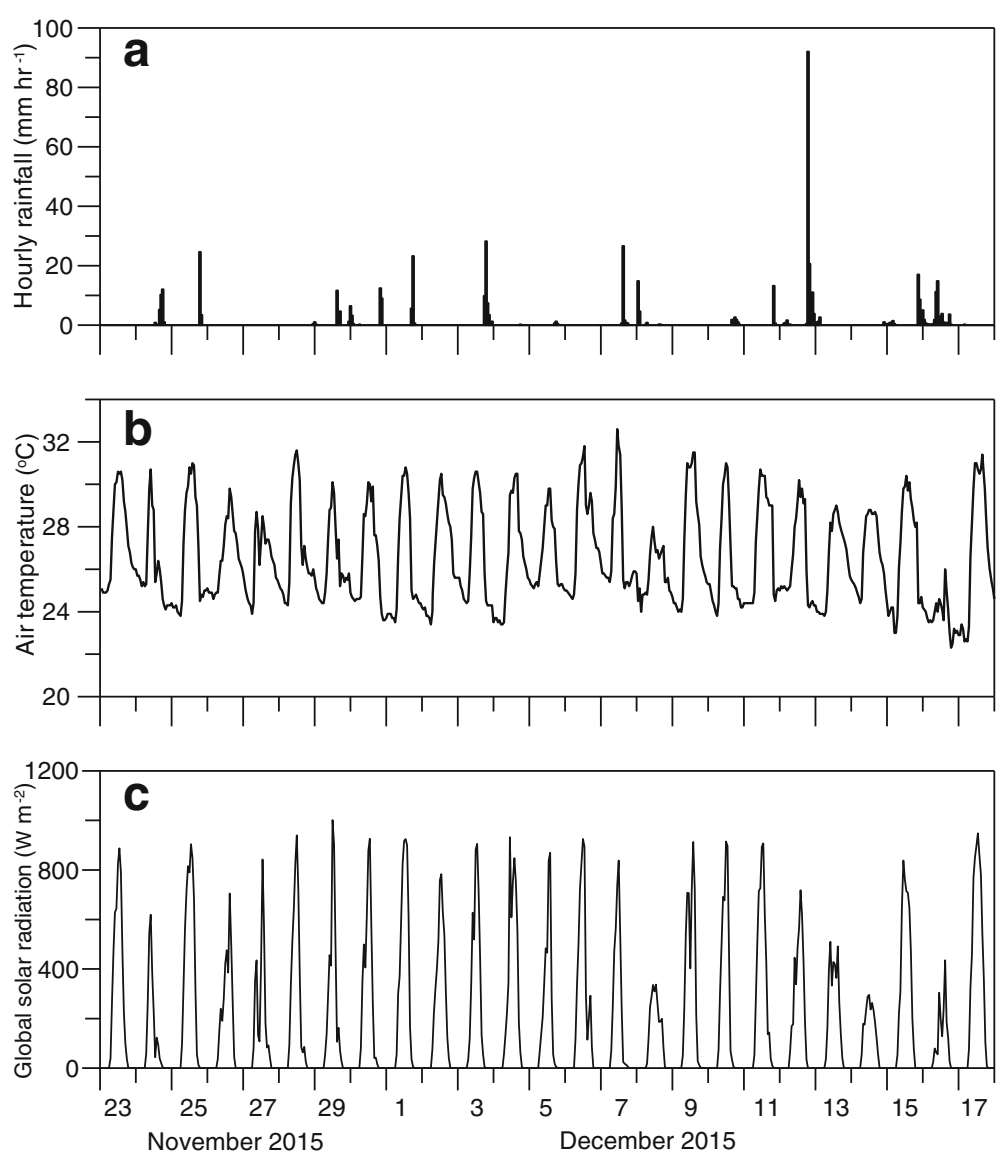

Fig. 2 Time series of a hourly total rainfall, $\mathbf{b}$ hourly averaged surface air temperature, and $\mathbf{c}$ hourly averaged global solar radiation observed at Bengkulu Meteorological Observatory ( $3^{\circ} 51^{\prime} 30^{\prime \prime} \mathrm{S} 102^{\circ} 20^{\prime} 11^{\prime \prime}$ E) on Sumatra Island from 23 November to 17 December 2015. The tick marks in the abscissa indicate $00 \mathrm{LT}$ for each of the days within the time period shown

in the present study showed strong solar radiation and the regular occurrence of precipitation on the island in the late afternoon prior to the beginning of the local active phase of the MJO until 12 December (except for 8 December), which is consistent with the results reported in previous studies. After 13 December, during the passage of the active phase of the MJO, convection frequently shifted eastward from the Indian Ocean to the island, whereas afternoon convection over the island was suppressed because of strong prevailing winds and lower solar insolation. The daily average amount of rainfall observed at Bengkulu during the local active phase of the MJO was less than that before its arrival.

Summarizing the results of this section, during the study period, strong solar radiation caused a clear diurnal cycle in surface air temperatures on most days on the western coast of Sumatra Island, even during an active phase of the MJO. The daily maximum air temperature occurred during the several hours before and after noon, with the minimum occurring in the early morning, before sunrise.
Diurnal variations of sea surface temperature, surface air temperature, rainfall, and solar radiation over the sea off the western coast of Sumatra Island

The time series of hourly total rainfall, hourly averaged sea surface temperature (SST), surface air temperature, and global solar radiation observed over the sea onboard the research vessel Mirai from 23 November to 17 December 2015 are shown in Fig. 4. Hourly mean sea surface temperatures greater than $29{ }^{\circ} \mathrm{C}$ were observed throughout the observation period, with an average SST of $29.7^{\circ} \mathrm{C}$ over the whole observation period. Before the active phase of the MJO, i.e., until 12 December, there were continuous fluctuations in the SST, and an hourly SST greater than $30{ }^{\circ} \mathrm{C}$ was frequently recorded. Subsequently, in the local active phase of the MJO, the SST decreased gradually from $29.6{ }^{\circ} \mathrm{C}$ on 13 December to $29.3{ }^{\circ} \mathrm{C}$ on 16 December. The decrease in sea surface temperature was attributed to the strong prevailing winds and lower solar insolation during this period. During the passage of the active MJO over the Maritime Continent from 13 to 22 December, westerly wind bursts 

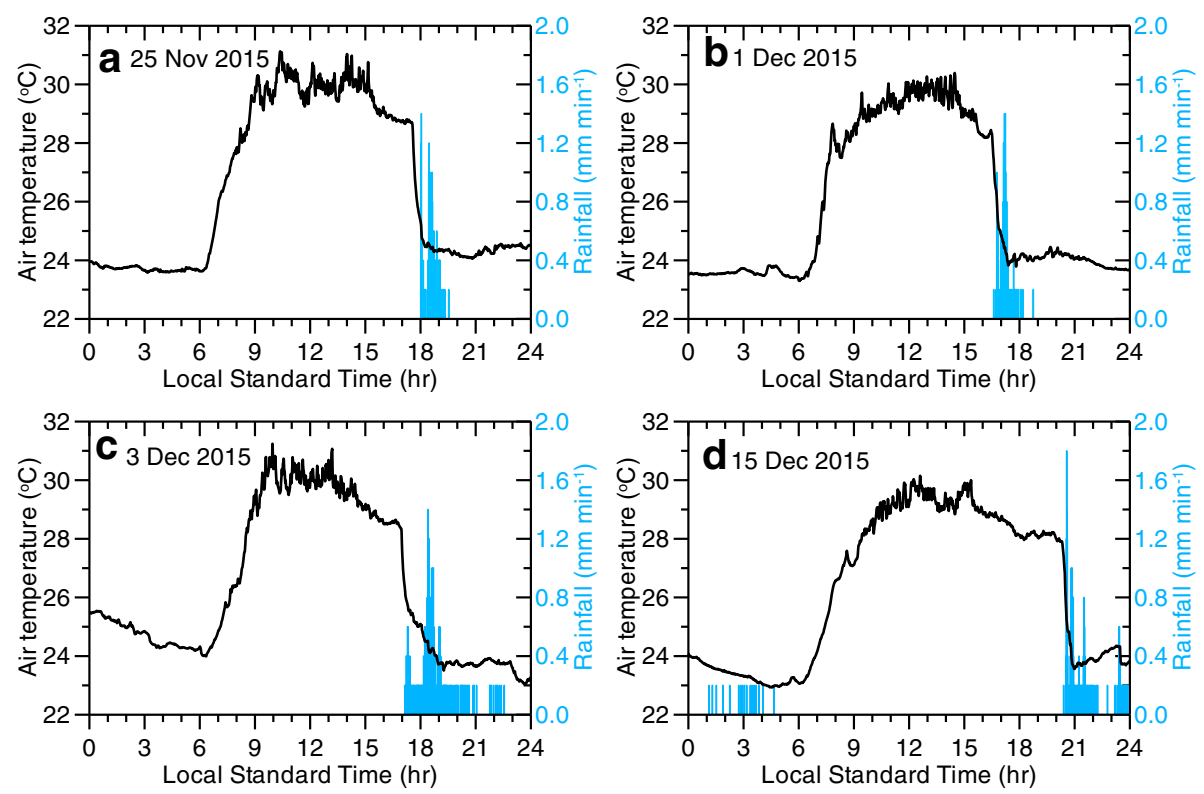

Fig. 3 Time series of surface air temperature and precipitation observed at Bengkulu Meteorological Observatory on Sumatra Island for a) 25 November, b) 1, c) 3 and d) 15 December 2015 at intervals of 1 min

were observed in the region ( $\mathrm{Wu}$ et al. 2017). These strong winds increased evaporation from the sea surface, which in turn led to a decrease in the SST. Meanwhile, a lower than normal daily maximum hourly mean global solar radiation was recorded from 13 to 16 December (except for 15 December), due to the cloudy conditions in the active phase of the MJO. On 17 December, the SST increased during the daytime due to the strong solar radiation and weaker near-surface wind. On 15 December, solar radiation was relatively strong while SST remained low, which suggests that strong winds may contribute greatly, although detailed evaluation on the relative roles of solar radiation and wind is necessary for further verification.

Rainfall was observed onboard the research vessel Mirai on 21 days during the observation period of 25 days. Prior to the local active phase of the MJO, most of the rainfall occurred near midnight over a period of 1 to $2 \mathrm{~h}$. The daily maximum rainfall was observed around $2300 \mathrm{LT}$ on average, about $4 \mathrm{~h}$ later than at Bengkulu on the western coast of Sumatra Island. Strong solar radiation was observed on most days, even those with heavy rain. On days with rain, strong solar radiation was still observed because rainfall was concentrated mostly after sunset. On these days, there was a daily maximum hourly mean air temperature of around $29{ }^{\circ} \mathrm{C}$, about $1.0^{\circ} \mathrm{C}$ lower than that over the land.

The temporal variations of surface air temperature and precipitation observed on the research vessel Mirai off the western coast of Sumatra Island for four consecutive days, from 10 to 13 December 2015, are shown in Fig. 5.
From Fig. 5, it can be seen that a sudden drop in air temperature occurred from the late afternoon to nighttime prior to the local active phase of the MJO, accompanied by the occurrence of precipitation at the observation site. After the rain stopped, air temperatures increased gradually. Then, the air temperatures dropped again when the next rainfall event occurred. If the drop in air temperatures was caused by radiative cooling of the sea surface, the decrease in air temperatures should have continued until the following morning, because radiative cooling would continue throughout the nighttime. The increase in air temperature was due to the air being heated by the warm water, because during the nighttime, there was no solar irradiance to heat the sea surface. On 13 December 2015 when the active phase of the MJO passed over the Maritime Continent, a drop in surface air temperature occurred during the daytime, corresponding to the occurrence of precipitation. Therefore, it is reasonable to conclude that the variations of surface air temperature over the sea were caused by a drop in temperature associated with precipitation, and the subsequent increase in temperature resulted from heating by the warm water.

Figure 6 shows a comparison of the diurnal changes in the surface air temperature observed at Bengkulu on the western coast and over the sea onboard the research vessel Mirai, before and during the local active phase of the MJO. Surface air temperatures on the island displayed a clear diurnal cycle both before and during the active phase of the MJO. In contrast, air temperatures over the sea varied little within a day, with the lowest temperatures 

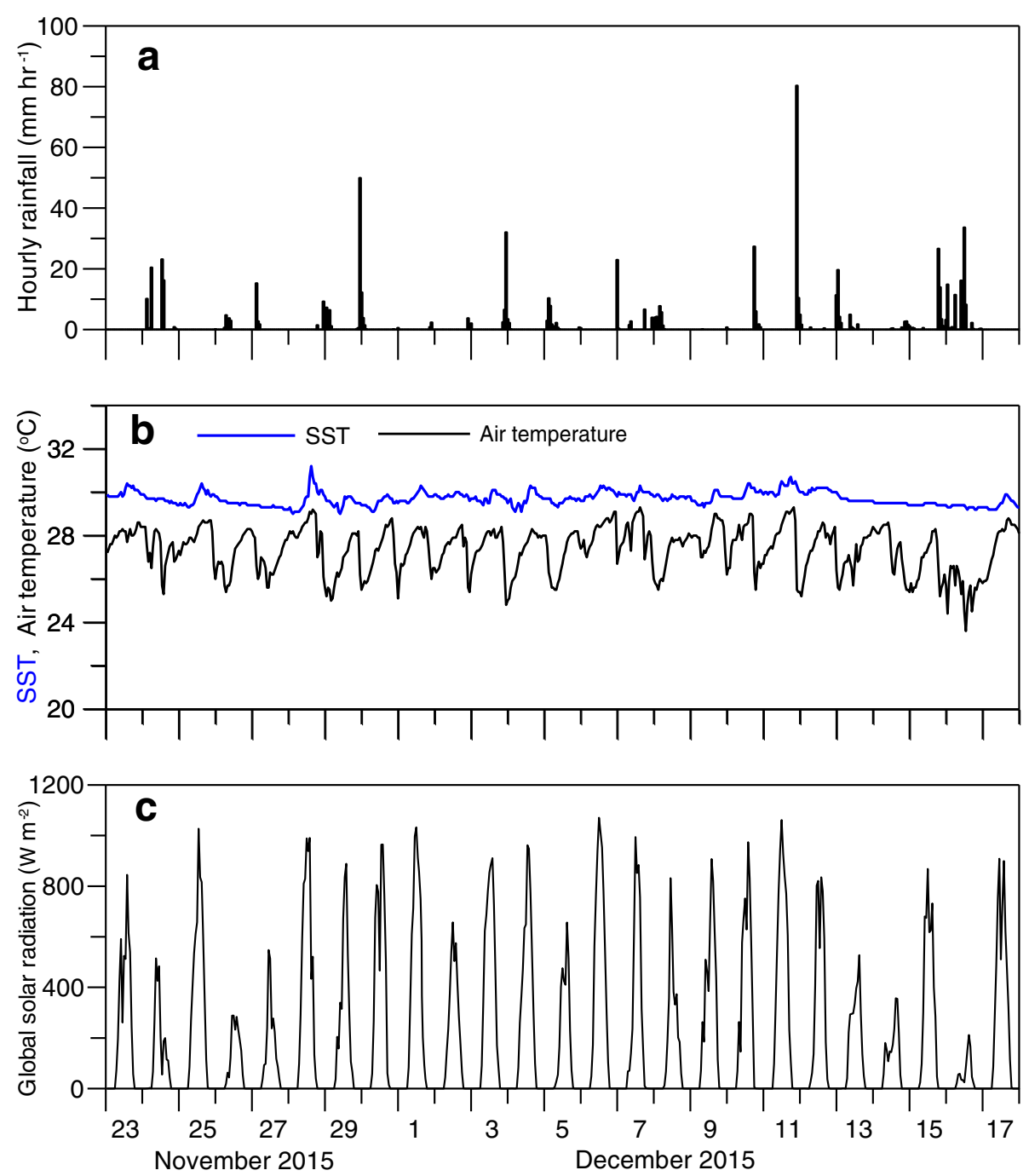

Fig. 4 Time series of a hourly total rainfall, $\mathbf{b}$ hourly averaged sea surface and sea air temperature (depth $=5 \mathrm{~m}$ ), and $\mathbf{c}$ hourly averaged global solar radiation observed by the research vessel Mirai. Stationary ship observations were carried out at $4^{\circ} 04^{\prime} 00^{\prime \prime} \mathrm{S} 101^{\circ} 54^{\prime} 00^{\prime \prime} \mathrm{E}, 50 \mathrm{~km}$ off the western coast of Sumatra Island from 23 November to 17 December 2015. The tick marks in the abscissa indicate 00 LT for each of the days within the time period shown

occurring near midnight. Daily mean air temperatures decreased during the local active phase of the MJO, both over the land and sea. However, over the land, air temperatures in the evening did not decrease during the local active phase of the MJO.

The decrease in air temperature over the sea in the afternoon and evening during the active MJO corresponds to the increased rainfall in the afternoon and evening. Wu et al. (2008) investigated the diurnal cycle of convection over western Kalimantan (Borneo) Island and the adjacent seas. Their results suggest that the evaporative cooling from convection associated with rain, which frequently occurs in the afternoon on the island, causes a rapid drop in air temperature in the lower atmosphere in the evening. This produces a strong temperature contrast between the land and the sea, with lower temperatures occurring over the island. As mentioned previously, before the onset of the active phase of the MJO, rainfall on Sumatra Island frequently occurred over a short period of time in the late afternoon and evening. Similar decreases in air temperature in the evening caused by evaporative cooling associated with rain occurred over the western coast of Sumatra Island (Wu et al. 2009). Therefore, the rapid drop in air temperature over the sea at nighttime can be attributed to precipitation cooling of the lower atmosphere.

To summarize, the air temperature decreased over both the land and sea during an active phase of the MJO. However, air temperatures during the early morning hours over the sea varied little before and during the active MJO. A sudden drop in air temperature frequently 

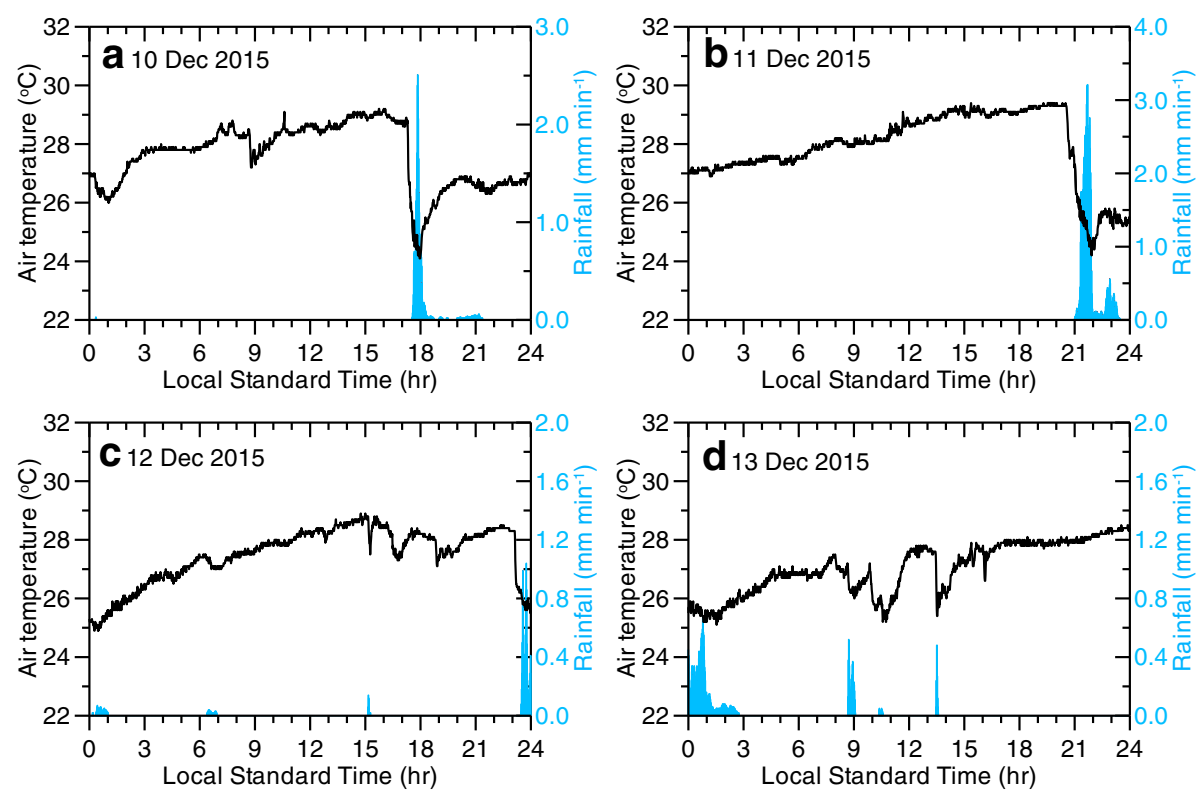

Fig. 5 Time series of surface air temperature and precipitation off the western coast of Sumatra Island observed by the research vessel Mirai for four consecutive days from a) 10, b) 11, c) 12 and d) 13 December 2015 at intervals of 1 min

occurred over the sea at nighttime and was caused by precipitation cooling.

Surface air temperature differences between the land and the sea on the western coast of Sumatra Island before and during an active phase of the MJO

A time series of air temperature differences between the land (at Bengkulu) and the adjacent sea (onboard the research vessel Mirai) from 23 November to 17 December 2015 is shown in Fig. 7. Although air temperature decreased during the local active phase of the MJO
(Figs. 2, 4, and 6), the land-sea air temperature contrasts during the active MJO (13-17 December) were almost the same as those before the onset of the active MJO. Except for the 2 days of 8 and 16 December, higher temperatures were observed on the island than over the sea during the daytime. On these 2 days, rain occurred on the island in the morning and continued throughout the afternoon, with a daily maximum hourly mean global solar radiation of less than $500 \mathrm{~W} \mathrm{~m}^{-2}$ on the island (Fig. 2). The cloudy conditions prevented the land from heating up rapidly during the daytime, and the sustained

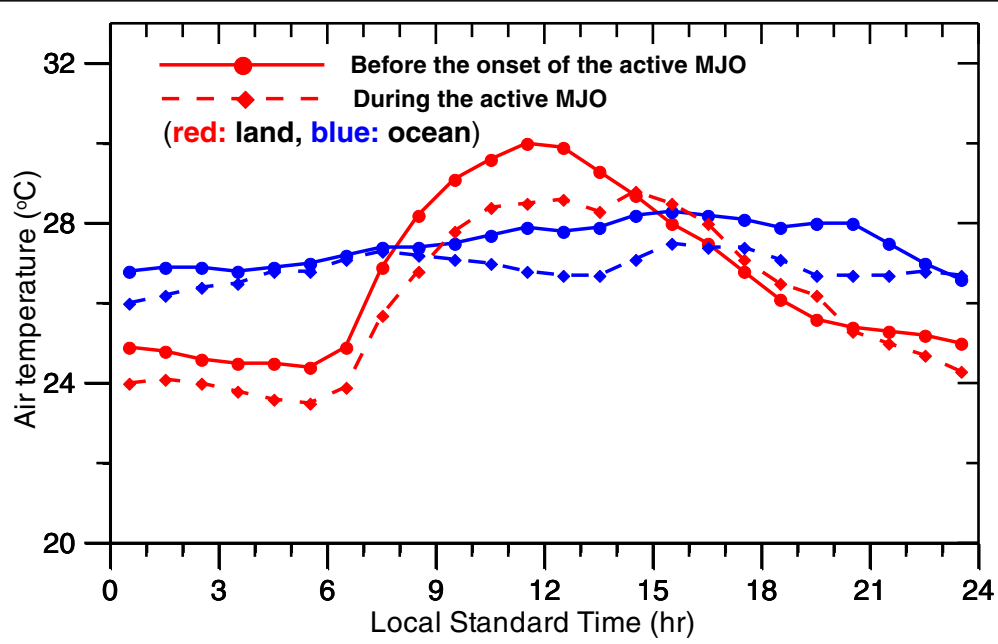

Fig. 6 A comparison between the diurnal changes in the hourly mean air temperature observed at Bengkulu on the western coast (red lines) and over the sea on the research vessel Mirai (blue lines), before the onset of the active MJO (solid lines) and averaged over 23 November to 12 December and during the active MJO (broken lines) averaged over 13 to 17 December 2015 


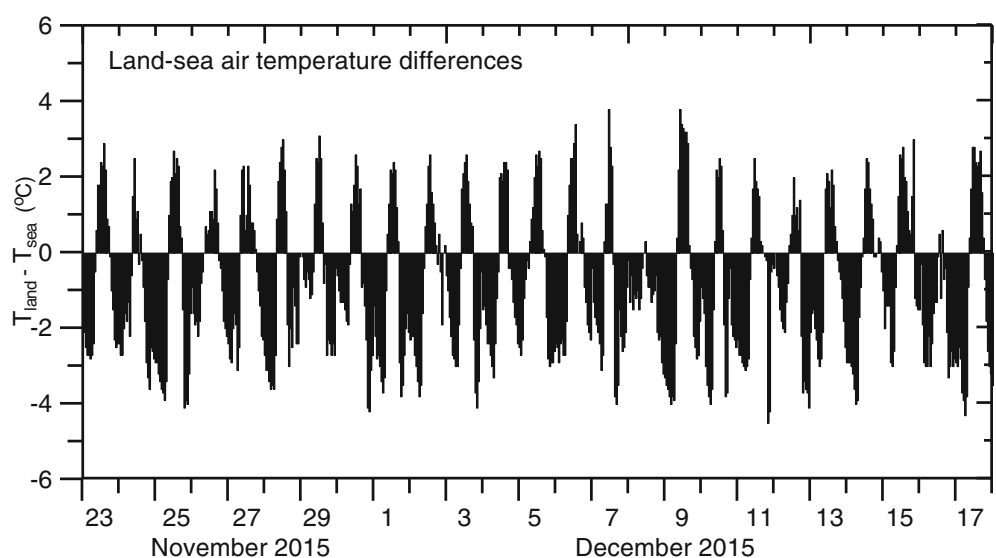

Fig. 7 Time series of air temperature differences between the land (at Bengkulu) and the adjacent sea (on the research vessel Mirai) from 23 November to 17 December 2015. Positive values indicate higher temperatures on the land, and negative values indicate higher temperatures over the sea. The tick marks in the abscissa indicate $00 \mathrm{LT}$ for each of the days within the time period shown

rain cooled the land surface. On the other hand, a higher temperature over the sea occurred from night until the early morning on all days during the observations.

Figure 8 shows a comparison of the diurnal changes in air temperature differences between the land and sea, before and during the local active phase of the MJO. It can be seen that before the onset of the active $\mathrm{MJO}$, a dual maxima of higher surface air temperatures over the sea compared to over the land occurred in the evening and early morning. As described previously, before the local active phase of the MJO, rainfall frequently occurred on the island in the late afternoon and evening.
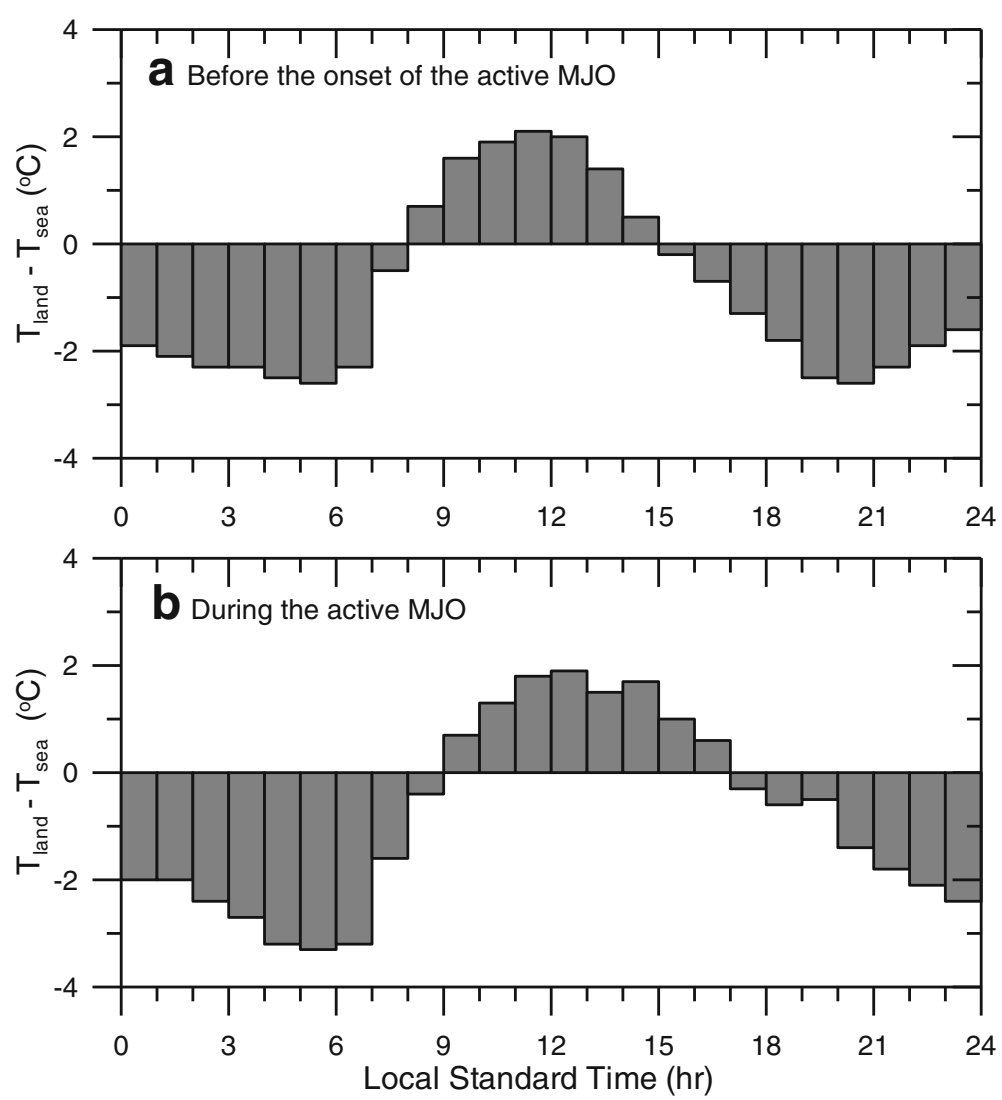

Fig. 8 A comparison of the diurnal changes in surface air temperature differences between the land and sea, a before the onset of the active MJO averaged over 23 November to 12 December and $\mathbf{b}$ during the active MJO averaged over 13 to 17 December 2015 
The large decreases in air temperature in the evening on land were caused by rain evaporative cooling of air in the low troposphere and cooling of the land surface by precipitation (Wu et al. 2008; Wu et al. 2009). As a result, there was a higher maximum air temperature over the sea than over the land in the evening. On the other hand, before the onset of the active MJO, the higher maximum temperatures over the sea than over the land in the early morning were considered to result from the nighttime radiative cooling of the land surface.

During the active phase of the MJO, in spite of the cloudy conditions, there were still large temperature contrasts during the daytime and in the morning. The temperature difference in the morning during the active phase of the MJO was even larger than that before the onset of the active MJO, i.e., 3.2 and $2.6{ }^{\circ} \mathrm{C}$, respectively. In an active phase of the $\mathrm{MJO}$, enhanced convection develops. The cloudy sky would then prevent the land from heating up rapidly in the daytime and cooling off rapidly at night. Therefore, it would be expected that the air temperature contrast between the land and the sea would be weaker. This is true in the mid-latitudes, where land-sea temperature differences are the result of daytime solar heating and nighttime radiative cooling of the land surface. However, the situation in the nearequatorial area of western Sumatra Island is a little different. As shown in Fig. 6, air temperatures on the land from late night to early morning during the active MJO were lower than before the onset of the active MJO, over both the land and the sea, due to precipitation cooling and the lower daytime solar insolation. However, there was still a clear diurnal cycle in the air temperatures over the land in the active MJO. On the other hand, because of the higher heat capacity of water, sea surface temperatures greater than $29{ }^{\circ} \mathrm{C}$ continued during the active phase of the MJO (Fig. 4). Air temperatures over the sea changed little during the early morning hours in the active MJO, while air temperatures decreased over the land. As a consequence, the temperature differences in the morning during the active MJO were larger than those before the onset of the active MJO.

The large temperature differences between the land and sea with lower temperatures occurring on the island during the night to early morning in an active phase of the MJO would induce strong offshore land breezes on the coast, because the strength of the land-sea breezes is directly proportional to the temperature difference between the land and the sea. A stronger offshore land breeze during the active MJO compared to before the onset of the active MJO was observed in the early morning (not shown) during the pre-YMC field campaign, which probably caused wind divergences in the lower troposphere, suppressing convection over the island. Further studies based on numerical experiments with the aid of atmospheric circulation models are needed to reveal the detailed physical mechanism by which the MJO interacts with local processes, such as the sea and land breeze circulations, to influence precipitation over the region.

\section{Conclusions}

This study investigated surface air temperature over the land and adjacent sea of the western coast of Sumatra Island and the land-sea surface temperature contrast before and during an active phase of the MJO using observation data obtained from the pre-YMC field campaign from November to December 2015. Over the land, although air temperatures decreased during the local active phase of the MJO, on most days, solar insolation enabled a clear diurnal cycle in air temperature to develop. A sudden drop in surface air temperature frequently occurred on the island in the late afternoon and over the sea at nighttime, due to precipitation cooling. While there was a higher temperature over the island than over the sea during the daytime on most of the days, there was a lower temperature over the island from the night to early morning.

Before an active phase of the MJO, a dual maxima of higher surface air temperatures over the sea compared to over the land occurred in the evening and early morning. The higher air temperature over the sea than over the land in the evening was caused by a decrease in air temperature over the land due to precipitation cooling. Then, during the local active phase of the MJO, under cloudy conditions, there were still large temperature contrasts during the daytime and in the early morning. Unlike in the midlatitudes, in the near-equatorial area in addition to the nighttime radiative cooling of the land surface, the decrease in air temperature over the land due to precipitation cooling and the lower solar insolation in the local active phase of the MJO caused large land-sea temperature contrasts in the morning. These results suggest that the decrease in air temperature caused by precipitation cooling had a substantial effect on the land-sea surface air temperature contrast on the western coast of Sumatra Island, particularly during an active phase of the MJO.

This study examined the land-sea surface temperature contrast on the western coast of Sumatra Island using surface observation data obtained from the pre-YMC field campaign. Evaporative cooling associated with precipitation is expected to produce deeper layers of cool air in the lower troposphere than radiative cooling of the land surface, which will cause stronger land-sea breezes. Therefore, further studies are needed to elucidate the profile of the land-sea temperature contrast in the lower troposphere caused by precipitation cooling using balloon sounding data from the pre-YMC field campaign. 


\section{Abbreviations}

BPPT: Indonesian Agency for Assessment and Application of Technology; JAMSTEC: Japan Agency for Marine-Earth Science and Technology; MJO: Madden-Julian Oscillation; SST: Sea surface temperature; YMC: Years of the Maritime Continent

\section{Acknowledgements}

We thank Dr. Kunio Yoneyama, Director of the Department of Coupled Ocean-Atmosphere-Land Processes Research of JAMSTEC, for his supervision and encouragement in this study. We also thank Mr. Agus Lacuda, the head of the Meteorological Station of Fatmawati Soekarno Airport in Bengkulu, Indonesia, for his strong support in the observations of this study.

\section{Funding}

This work was supported by the JAMSTEC pre-YMC project. PW was partly funded by JSPS KAKENHI Grant Number 15K01167.

\section{Authors' contributions}

PW proposed the topic and conceived and designed the study. SM and PW carried out the observations. FS and SM led the observations and collaborated with the corresponding author in the construction of manuscript. All authors read and approved the final manuscript.

\section{Authors' information}

PW is a Senior Scientist of the Department of Coupled Ocean-AtmosphereLand Processes Research (DCOP), Japan Agency for Marine-Earth Science and Technology (JAMSTEC). SM is the Vice Director and a Principal Technical Scientist of DCOP, JAMSTEC. FS is a Principal Investigator at the Center of Regional Resources Development Technology (CRRDT), Agency for the Assessment and Application of Technology (BPPT), Indonesia.

\section{Competing interests}

The authors declare that they have no competing interests.

\section{Publisher's Note}

Springer Nature remains neutral with regard to jurisdictional claims in published maps and institutional affiliations.

\section{Author details}

'Japan Agency for Marine-Earth Science and Technology, 2-15 Natsushima-cho, Yokosuka-City, Kanagawa 237-0061, Japan. ${ }^{2}$ Indonesian Agency for Assessment and Application of Technology, Jl. Raya Puspiptek, South Tangerang 15314, Indonesia.

Received: 7 July 2017 Accepted: 14 December 2017

Published online: 10 January 2018

\section{References}

Araki R, Yamanaka MD, Murata F, Hashiguchi H, Oku Y, Sribimawati T, Kudsy M, Renggono F (2006) Seasonal and interannual variations of diurnal cycles of wind and cloud activity observed at Serpong, West Jawa, Indonesia. J Meteor Soc Japan 84A:171-194. https://doi.org/10.2151/jmsj.84A.171

Birch C, Webster S, Peatman SC, Parker D, Matthews AJ, Li Y, Hassim M (2016) Scale interactions between the MJO and the western Maritime Continent. J Clim 29:2471-2492. https://doi.org/10.1175/JCLI-D-15-0557.1

Deser C, Wallace JM (1990) Large-scale atmospheric circulation features of warm and cold episodes in the tropical Pacific. J Clim 3:1254-1281

Fujita M, Yoneyama K, Mori S, Nasuno T, Satoh M (2011) Diurnal convection peaks over the Eastern Indian Ocean off Sumatra during different MJO phases. J Meteor Soc Japan 89A:317-330

Hamada JI, Yamanaka MD, Matsumoto J, Fukao S, Winarso PA, Sribimawati T (2002) Spatial and temporal variations of the rainy season over Indonesia and their link to ENSO. J Meteor Soc Japan 80:285-310

Hara M, Yoshikane T, Takahashi HG, Kimura F, Noda A, Tokioka T (2009) Assessment of the diurnal cycle of precipitation over the Maritime Continent simulated by a 20 km mesh GCM using TRMM PR data. J Meteor Soc Japan 87A:413-424. https://doi.org/10.2151/jmsj.87A.413

JAMSTEC (2016) RN Mirai Cruise Report MR15-04: The observational study of the heavy rainfall zone in the eastern Indian Ocean. http://www.godac.jamstec. go.jp/catalog/data/doc_catalog/media/MR15-04_all.pdf. Accessed 5 Feb 2016
Peatman SC, Matthews AJ, Stevens DP (2014) Propagation of the MaddenJulian Oscillation through the Maritime Continent and scale interaction with the diurnal cycle of precipitation. Q J R Meteorol Soc 140:814-825. https://doi.org/10.1002/qj.2161

Rauniyar P, Walsh K (2011) Scale interaction of the diurnal cycle of rainfall over the Maritime Continent and Australia: influence of the MJO. J Clim 24:325348. https://doi.org/10.1175/2010JCLI3673.1

Saji NH, Goswami BN, Vinayachandran PN, Yamagata T (1999) A dipole mode in the tropical Indian Ocean. Nature 401:360-363. https://doi.org/10.1038/43855

Wheeler M, Hendon H (2004) An all-season real-time multivariate MJO index: development of an index for monitoring and prediction. Mon Wea Rev 132: 1917-1932

Wu P, Hamada J, Mori S, Tauhid Yl, Yamanaka MD, Kimura F (2003) Diurnal variation of precipitable water over a mountainous area of Sumatra Island. J Appl Meteorol 42:1107-1115

Wu P, Yamanaka MD, Matsumoto J (2008) The formation of nocturnal rainfall offshore from convection over western Kalimantan (Borneo) Island. J Meteor Soc Japan 86A:187-203

Wu P, Hara M, Hamada J, Yamanaka MD, Kimura F (2009) Why a large amount of rain falls over the sea in the vicinity of western Sumatra Island during nighttime. J Appl Meteor Climatol 48:1345-1361. https:/doi.org/10.1175/2009JAMC2052.1

Wu P, Ardiansyah D, Yokoi S, Mori S, Syamsudin F, Yoneyama K (2017) Why torrential rain occurs on the western coast of Sumatra Island at the leading edge of the MJO westerly wind bursts. SOLA 13:36-40. https://doi.org/10.2151/sola.2017-007

Yamanaka MD (2016) Physical climatology of Indonesian maritime continent: an outline to comprehend observational studies. Atmos Res 178-179:231-259. https://doi.org/10.1016/j.atmosres.2016.03.017

\section{Submit your manuscript to a SpringerOpen ${ }^{\mathcal{O}}$ journal and benefit from:}

- Convenient online submission

- Rigorous peer review

- Open access: articles freely available online

- High visibility within the field

- Retaining the copyright to your article

Submit your next manuscript at $>$ springeropen.com 